Editorial

\title{
Administrative Sciences: An International Journal on the Science of Administration
}

\author{
Robert G. DelCampo \\ Founding Editor-in-Chief of Administrative Sciences, Anderson School of Management, \\ University of New Mexico, Albuquerque, NM 87131,USA; E-Mail: delcampo@mgt.unm.edu; \\ Tel.: +1 5052770018
}

Received: 4 October 2010 / Accepted: 12 October 2010 / Published: 12 October 2010

In the past thirty years, academic work in the field of business has evolved from an applied field to a theoretically grounded, rigorous, scientific field of inquiry garnering the attention of renowned academics from the fields of psychology, sociology, economics, political science, and many others. To date, the social science of administration has developed into a multi-faceted field with theoretical and empirical faces too numerous to mention. With this development, the need for innovations in scholarly publication in this area has arisen; one of these being the introduction of our new journal, Administrative Sciences.

Administrative Sciences is conceived as an inter-disciplinary journal aimed at publishing high quality developments in empiricism and theory from a myriad of disciplines. It is our aim to encourage boundary spanning contributions from fundamental business disciplines such as management, ethics, strategy, marketing, accounting and finance, but also to link developments in these areas back to the foundational social science fields of psychology, sociology, economics and the like. Administrative Sciences will rely on MDPI's expertise in accelerating the delivery of research to scholars by removing the sometimes overwhelming influence of production schedules on (printed) journal publication timetables. By coordinating the peer-review procedure from the editorial office and by applying simple yet effective peer-review standards, publication speed can be increased. Quality will not be reduced. The editorial staff will make every effort to ensure a swift peer-review and editorial process without compromising the highest standards of peer-review.

\section{Why a new journal?}

Our field has several outlets for scholarly work-so, what makes this journal different? I too was curious when MDPI approached me. There are a number of significant factors that define Administrative Sciences as revolutionary in its approach to academic publishing. 
First, we have all become accustomed to spectacular delays in publication and incredibly high institutional subscription costs associated with most journals. In the "publish or perish" world of academia and with the current economic flux of most institutions, most publication outlets are inaccessible for the bulk of the academic community.

MDPI's approach is markedly different. Administrative Sciences will follow peer-reviewing practices from the natural sciences, which shifts a tremendous amount of the administrative burden of the process to the professional in-house editors. Further, Administrative Sciences is an open access journal, meaning that no reader or institution will ever be charged a fee for accessing its content. The costs associated with the journal's publication are covered by an Article Processing Charge (APC) paid by the authors, which is lower than the page charges in a number of other journals in this domain.

In order to generate interest and quality submissions to Administrative Sciences, MDPI has agreed to waive all APCs for manuscripts submitted in 2010 and 2011. Open access publishing removes the barriers between the researcher and their audience, so that work can be read and cited by the widest possible audience. As a forward thinking publication, Administrative Sciences offers its full content as open access.

\section{What will Administrative Sciences publish?}

Our discipline develops on a day-to-day basis and so will our journal. Administrative Sciences will provide comprehensive and open-minded approaches to the science of administration. We aim to advance and communicate knowledge concerning organization theory, strategic management, public administration, as well as interdisciplinary research in related fields, such as business, economics, sociology, physiology, communication theory or artificial intelligence, and their implications on management, organizations and society. So which fields does this encompass? What topics might be of the greatest impact? Areas of interest include organizational behavior, human resource management, public administration, innovation management, policy analysis, strategic management, governance, ethics, diversity, and a work-life balance, just to name a few.

Administrative Sciences will publish regular research articles, reviews and communications. There is no restriction on the length of the papers as we encourage researchers to publish their theoretical and empirical results in as much detail as possible. For theoretical papers, full details of proofs must be provided so that the results can be checked; similarly, for experimental papers, sufficient details must be provided so results can be reproduced.

We look forward to your submissions and input. Please feel free to contact me or the editorial staff at any time to discuss the direction of the journal or your interest in submitting work. Thank you for your time and consideration; and welcome to Administrative Sciences.

(C) 2010 by the authors; licensee MDPI, Basel, Switzerland. This article is an open access article distributed under the terms and conditions of the Creative Commons Attribution license (http://creativecommons.org/licenses/by/3.0/). 